\title{
Cystic echinococcosis therapy: Albendazole-loaded lipid nanocapsules enhance the oral bioavailability and efficacy in experimentally infected mice
}

\author{
Patricia E. Pensel ${ }^{\mathrm{a}, \mathrm{b}}$, Gabriela Ullio Gamboa ${ }^{\mathrm{c}, \mathrm{d}}$, Julia Fabbri ${ }^{\mathrm{a}, \mathrm{b}}$, Laura Ceballos ${ }^{\mathrm{e}}$, \\ Sergio Sanchez Bruni ${ }^{e}$, Luis I. Alvarez ${ }^{e}$, Daniel Allemandi ${ }^{c, d}$, Jean Pierre Benoit ${ }^{f}$, \\ Santiago D. Palma ${ }^{c, d}$, María C. Elissondo ${ }^{a, b, *}$ \\ a Laboratorio de Zoonosis Parasitaria, Departamento de Biología, Facultad de Ciencias Exactas y Naturales, Universidad Nacional de Mar del Plata, Funes \\ 3250, 7600 Mar del Plata, Argentina \\ ${ }^{\mathrm{b}}$ Consejo Nacional de Investigaciones Científicas y Técnicas (CONICET), Buenos Aires, Argentina \\ c Unidad de Investigación y Desarrollo en Tecnología Farmacéutica, UNITEFA-CONICET, Ciudad Universitaria, 5000 HUA, Córdoba, Argentina \\ d Departamento de Farmacia, Facultad de Ciencias Químicas, Universidad Nacional de Córdoba, Ciudad Universitaria, 5000 HUA, Córdoba, Argentina \\ e Laboratorio de Farmacología, Centro de Investigación Veterinaria de Tandil (CIVETAN), Facultad de Ciencias Veterinarias, UNCPBA-Tandil, Argentina \\ f LUNAM Université, Université d'Angers, INSERM U1066, IBS-CHU Angers, 4 rue Larrey, 49933 Angers, France
}

\section{A R T I C L E I N F O}

\section{Article history:}

Received 10 April 2015

Received in revised form 16 September 2015

Accepted 23 September 2015

Available online 26 September 2015

\section{Keywords:}

Lipid nanocapsules

Albendazole

Cystic echinococcosis

Echinococcus granulosus

\begin{abstract}
A B S T R A C T
Therapeutic failures attributed to medical management of cystic echinococcosis (CE) with albendazole (ABZ) have been primarily linked to the poor drug absorption rate resulting in low drug level in plasma and hydatid cysts. Lipid nanocapsules (LNCs) represent nanocarriers designed to encapsulate lipophilic drugs, such as ABZ. The goals of the current work were: (i) to characterize the plasma and cyst drug exposure after the administration of ABZ as ABZ-LNCs or ABZ suspension (ABZ-SUSP) in mice infected with Echinococcus granulosus, and ii) to compare the clinical efficacies of both ABZ formulations. Enhanced ABZ sulphoxide (ABZ-SO) concentration profiles were obtained in plasma and cysts from ABZ-LNC treated animals. ABZSO exposure ( $\left.A_{U C} C_{0-\mathrm{LOQ}}\right)$ was significantly higher in plasma and cyst after the ABZ-LNC treatments, both orally and subcutaneously, compared to that observed after oral administration of ABZ-SUSP. Additionally, ABZSO concentrations measured in cysts from ABZ-LNC treated mice were 1.7-fold higher than those detected in plasma. This enhanced drug availability correlated with an increased efficacy against secondary CE in mice observed for the ABZ-LNCs, while ABZ-SUSP did not reach differences with the untreated control group. This new pharmacotechnically-based strategy could be a potential alternative to improve the treatment of human CE.
\end{abstract}

(C) 2015 Elsevier B.V. All rights reserved.

\section{Introduction}

Echinococcus granulosus is a tapeworm belonging to the family Taeniidae. This zoonotic parasite maintains itself primarily in a lifecycle between domestic dogs (definitive host) and domestic ungulates (intermediate host). Humans become infected by the ingestion of E. granulosus eggs shed in the feces of infected canids, resulting in cystic echinococcosis (CE) (Budke et al., 2013). CE, a chronic, complex, and still neglected infectious disease, is charac-

\footnotetext{
* Corresponding author at: Laboratorio de Zoonosis Parasitarias, Facultad de Ciencias Exactas y Naturales, Universidad Nacional de Mar del Plata (UNMdP), Funes 3250, 7600 Mar del Plata, Argentina. Fax: +54 2234753150

E-mail address: c.elissondo@gmail.com (M.C. Elissondo).
}

terized by cystic lesions, most commonly in the liver and lungs (Brunetti et al., 2011).

Depending on different factors such as cyst number, size and location, viability status, the involved organ and location, the interaction between the expanding parasite and the adjacent host tissue and bacterial and fungal infection, there are four treatment and management options for CE: surgery, percutaneous procedures, antiparasitic drug treatment or watch and wait (Stojkovic et al., 2009). The evidence supporting any of the treatment modalities from carefully designed clinical studies is insufficient. Consequently, the choice of appropriate options for patients remains controversial (Brunetti and White, 2012).

The drugs commonly used for anti-hydatid cysts treatment are benzimidazoles (BZ), such as albendazole (ABZ) and mebendazole (McManus et al., 2012). ABZ belongs to Class II of the biopharmaceutical classification system, with high permeability and low 
aqueous solubility $\left(0.2 \mu \mathrm{g} / \mathrm{ml}\right.$ in water at $\left.25^{\circ} \mathrm{C}\right)$ (Jung et al., 1998). Consequently, this compound has to be administrated at multiple doses in order to provide therapeutic concentrations and acceptable anthelmintic efficacy (Cook, 1990).

Approximately a third of the patients treated with BZ drugs have been cured, $30-50 \%$ develop some evidence of a therapeutic response while between 20 and $40 \%$ of cases do not respond favorably (Moro and Schantz, 2009).

Therapeutic failures attributed to medical management of CE with $A B Z$ have been primarily linked to the poor drug absorption rate $(<5 \%)$ resulting in low drug level in plasma and cysts (Shuhua et al., 2002). On the other hand, the poor water solubility of ABZ offers only few formulation possibilities, limiting the administration routes (Alanazi et al., 2007). Therefore, increasing the aqueous solubility and dissolution rate of $A B Z$ is a relevant goal to optimize the chemotherapeutic treatment of $C E$.

Regarding this, different efforts related to the formulation process have been made to enhance ABZ water solubility and dissolution rate such as soybean oil emulsion (Shuhua et al., 2002), liposomes (Dvorožňáková et al., 2004), cyclodextrins (PalomaresAlonso et al., 2010), and solid dispersions (Castro et al., 2012). In addition, several clinical studies have demonstrated that enhanced systemic availability of the parent drug/active metabolite obtained by increased drug absorption correlates with an improved antiparasitic effect (Shuhua et al., 2002; Dvorožňáková et al., 2004; Ceballos et al., 2008; Palomares-Alonso et al., 2010; Pensel et al., 2014).

Lipid nanocapsules (LNCs) represent nanocarriers designed to encapsulate lipophilic drugs without using organic solvents. An original phase-inversion process allows the production of nanocarriers ranging from 25 to $100 \mathrm{~nm}$ in a saline solution. The carrier has an unimodal size distribution and a low polydispersity index. Structurally, the lipophilic drug is solubilised into the central lipid core, which is surrounded by a membrane of lecithins and a pegylated surfactant (Heurtault et al., 2002). LNCs have shown potential for the delivery of many drugs by different routes, mainly parenteral (Lacoeuillea et al., 2007) as well as pulmonary (Hureaux et al., 2009) and more interestingly, the oral route (Peltier et al., 2006). The goals of the current work were: (i) to characterize the plasma and cyst drug exposure after the administration of ABZ as ABZ-LNCs or ABZSUSP in mice infected with E. granulosus, and (ii) to compare the clinical efficacies of both ABZ formulations.

\section{Materials and methods}

\subsection{Chemicals}

Reference standards of ABZ, ABZ-SO, $\mathrm{ABZ}-\mathrm{SO}_{2}$ and oxibendazole (OBZ) (used as an internal standard) were purchased from Sigma-Aldrich (Dorset, United Kingdom). The solvents used for the chemical extraction and chromatographic analysis were highperformance liquid chromatography (HPLC) grade (Baker, Inc., Phillipsburg, NJ) and purified water was obtained from a MilliQ185 System (Millipore, Paris, France).

The lipophilic Labrafac ${ }^{\circledR}$ WL 1349 (caprylic-capric acid triglycerides, European Pharmacopeia, IVth, 2002) and oleic acid were provided by Gattefossé (Saint-Priest, France). Lipoïd ${ }^{\circledR}$ S75-3 (soybean lecithin containing at least $69 \%$ of phosphatidylcholine) and Solutol ${ }^{\circledR}$ HS15 were gifts from Lipoïd Gmbh (Ludwigshafen, Germany) and BASF (Ludwigshafen, Germany), respectively. $\mathrm{NaCl}$ was purchased from Prolabo VWR International (Fontenay-sousBois, France).

\subsection{ABZ formulations}

LNCs were prepared according to a modified process originally based on the work of Heurtault et al. (2002). Briefly, $5 \mathrm{mg}$ of ABZ was dissolved in oleic acid at $80^{\circ} \mathrm{C}$ and mixed with Labrafac (Gatefosse, France). Then, Lipoid ${ }^{\circledR}$ S75-3 was added and the mixture was heated again to solubilize Lipoid ${ }^{\circledR}$. After cooling, Solutol ${ }^{\circledR}$ HS15, $\mathrm{NaCl}$ and water were added and homogenized under magnetic stirring. Three cycles of progressive heating and cooling between 60 and $90^{\circ} \mathrm{C}$ were then performed and at $75^{\circ} \mathrm{C}$ during the last cycle, an irreversible shock was induced by dilution with cold water $(12.5 \mathrm{ml}$ at $2{ }^{\circ} \mathrm{C}$ ). Afterward, a slow magnetic stirring was applied to the suspension of LNCs for $5 \mathrm{~min}$ at room temperature and a final concentration of $0.28 \mathrm{mg} / \mathrm{ml}$ was achieved.

ABZ-SUSP $(0.28 \mathrm{mg} / \mathrm{ml})$ was prepared by mixing the dissolution of $A B Z$ pure standard in deionized water $(\mathrm{pH} 7.0)$ under shaking for $12 \mathrm{~h}$. Before its administration to mice, ABZ-SUSP was vigorously shaken.

ABZSO was dissolved in dimethyl sulphoxide (DMSO) at a drug concentration of $0.1 \mathrm{mg} / \mathrm{ml}$ and was added to the medium 199 (Gibco BRL) resulting in final concentrations of $1.5,1$ and $0.5 \mu \mathrm{g} / \mathrm{ml}$. The final volume of drug solution added to the medium was $0.15 \%$. Control culture contained 0.15\% DMSO.

\subsection{Protoscolex collection}

Protoscoleces show the capacity of being able to mature into strobilar adult stages, when ingested by a definitive canid host, but also of 're-differentiating' into fully developed cysts when released into the intermediate host body cavity upon cyst rupture (Smyth et al., 1966). Protoscoleces of E. granulosus were collected aseptically from liver and lung hydatid cysts of infected cattle slaughtered in an abattoir located in the southeast of Buenos Aires province, Argentina. Viability was assessed by the methylene blue exclusion test (Elissondo et al., 2006).

\subsection{Experimental animals}

Animal procedures and management protocols were approved by the Institutional Animal Care and Use Committee (act 255507-14) of the Faculty of Exact and Natural Sciences, National University of Mar del Plata, Mar del Plata, Argentina and carried out in accordance with the 2011 revised form of The Guide for the Care and Use of Laboratory Animals published by the U.S. National Institutes of Health. Unnecessary animal suffering was avoided throughout the study. Female CF-1 mice ( 5 months old at the start of the experiments) were used. The animals were housed in a temperature-controlled $\left(22 \pm 1^{\circ} \mathrm{C}\right)$, light-cycled (12-h light/dark cycle) room. Food and water were given ad libitum.

\subsection{Experimental design}

\subsubsection{Pharmacokinetic study}

One hundred thirty-two (132) mice were infected by intraperitoneal (i.p.) inoculation of 1500 protoscoleces/animal, suspended in $0.5 \mathrm{ml}$ of medium 199 (Gibco). Five months post-infection (p.i), animals received the following treatments: $A B Z-\mathrm{LNCs}_{\text {oral }}$, animals were orally treated with $\mathrm{ABZ}$ as a LNC-based formulation; ABZ$\mathrm{LNCs}_{\mathrm{sc}}$, animals were subcutaneously (sc) treated with $\mathrm{ABZ}$ as a LNC-based formulation; and ABZ-SUSP oral, animals were orally treated with a suspension of ABZ. The oral dose was administered using an intragastric tube. All treatments were given as a single dose of $5 \mathrm{mg} / \mathrm{kg} \mathrm{ABZ}(0.53 \mathrm{ml} /$ animal). Blood and cyst samples were obtained from sacrificed animals ( $n=4$ per collection point) at the following times post-treatment: 5, 15, and $30 \mathrm{~min}$ and 1, 2, 4, 6, 8, 10,12 and $16 \mathrm{~h}$. Plasma was separated by centrifugation at $2000 \times g$ for $15 \mathrm{~min}$, placed into plastic tubes and frozen at $-20^{\circ} \mathrm{C}$ until analysis by HPLC. Cyst samples were washed several times with physiological solution and stored at $-20^{\circ} \mathrm{C}$ until analysis by HPLC. 
HPLC and pharmacokinetic analysis of the concentration data were as follows. Plasma $(100 \mu \mathrm{l})$ and cyst $(0.5 \mathrm{~g})$ samples were spiked with OBZ as an internal standard $(1 \mu \mathrm{g} / \mathrm{ml})$. After $5 \mathrm{~min}$, plasma and cyst samples were supplemented with $1.5 \mathrm{ml}$ of acetonitrile, HPLC grade. Later, samples were shaken for $15 \mathrm{~min}$ in a multitube vortexer (VWR Scientific Products, West Chester, PA, USA) and centrifuged at $3800 \times g$ for $10 \mathrm{~min}$. The supernatant was concentrated to dryness in a vacuum concentrator (Thermo Speed$\mathrm{Vac}^{\circledR}$, Milford, MA, USA) and then reconstituted with $150 \mu \mathrm{l}$ of mobile phase. Finally, $50 \mu \mathrm{l}$ of this solution was injected into the chromatographic system

Chromatography was performed on Shimadzu HPLC equipment (Shimadzu Corporation, Kyoto, Japan) with a UV-visible spectrophotometric detector (SPD-10A) reading at $292 \mathrm{~nm}$ and a C18 reversed-phase column ( $5 \mu \mathrm{m}, 250 \mathrm{~mm}$ by $4.6 \mathrm{~mm}$; Kromasil, Sweden) used for analysis of ABZ and its metabolites. The calibration curves for each analyte, constructed by least-squares linear regression analysis, showed good linearity, with correlation coefficients of 0.994 . Mean absolute recovery percentages in plasma and cysts for concentrations ranging between 0.01 and $2 \mu \mathrm{g} / \mathrm{ml}$

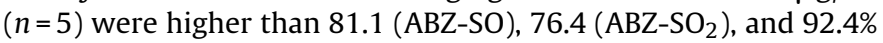
(ABZ), with coefficients of variation (CV) lower than 5.2, 4.3, and $6.4 \%$, respectively. The limit of quantification (LOQ) was defined as the lowest measured concentration with a CV of $\leq 20 \%$, accuracy of $\pm 20 \%$, and an absolute recovery of $\geq 70 \%$. The LOQ for ABZ and its metabolites were 0.1 and $0.05 \mu \mathrm{g} / \mathrm{ml}$ respectively.

The peak concentration $\left(C_{\max }\right)$ and time to peak concentration $\left(T_{\max }\right)$ were read from the plotted concentration-time curves of each analyte. The area under the concentration-time curve from 0 up to the limit of quantification $\left(\mathrm{AUC}_{0-\mathrm{LOQ}}\right)$ for $\mathrm{ABZ}$ and metabolites was calculated by the trapezoidal rule (Gibaldi and Perrier, 1982), using the PK Solutions computer program (Summit Research Services, Ashland, OH, USA).

\subsubsection{In vivo effect against secondary cysts of E. granulosus}

Female CF-1 mice ( $n=60$; body weight, $25 \pm 5 \mathrm{~g}$ ) were infected with E. granulosus protoscoleces as described above (see Section 2.5.1). Five months p.i., mice were allocated into the following experimental groups (10 animals/group): (a) Control group, animals receiving distilled water as a placebo; (b) Control Blank LNCs $_{\text {oral }}$ group, animals were treated with the LNCs formulation without drug by the oral route; (c) Control Blank $\mathrm{LNCS}_{\mathrm{sc}}$ group, animals were treated with the LNCs formulation without drug by the sc route; (d) ABZ-SUSP group, animals were treated with the suspension of $A B Z$ by the oral route; (e) ABZ-LNCs oral $_{\text {group, ani- }}$ mals were treated with the ABZ LNC-based formulation by the oral route; (f) ABZ-LNCs $s_{s c}$ group, animals were treated with the ABZ LNC-based formulation by the sc route. Treatments were performed daily during 30 days at the $\mathrm{ABZ}$ dose of $5 \mathrm{mg} / \mathrm{kg}(0.53 \mathrm{ml} / \mathrm{animal})$.

\subsection{Determination of parasite weight and efficacy rate of treatments}

At the end of treatment period, animals were euthanized, and necropsy was carried out immediately thereafter. The cysts were removed from the peritoneal cavity. The weight of the cysts collected from each animal was recorded using an analytical balance. The efficacy of treatments (based on the weight of cysts from infected mice), was calculated by use of the following formula:

Efficacy $=\frac{\left(X_{\mathrm{C}}-X_{\mathrm{T}}\right)}{X_{\mathrm{C}}} \times 100$,

where $X_{C}$ is the mean cyst weight in the untreated control group and $X_{\mathrm{T}}$ is the mean cysts weight in the treated group.

\subsection{Mouse infection and collection of cysts}

Female CF-1 mice were infected with E. granulosus protoscoleces as described above (see Section 2.5.1). At 8 months p.i., mice with experimental secondary CE were euthanized, and necropsy was carried out immediately thereafter. At necropsy, the peritoneal cavity was opened and the hydatid cysts were carefully removed (Elissondo et al., 2009)

\subsection{Procedures for in vitro incubation of cysts}

In order to evaluate the efficacy of ABZSO at low concentrations, groups of 10 cysts $(1-4 \mathrm{~mm})$ were placed in Leighton tubes containing $10 \mathrm{ml}$ of medium 199 with ABZSO at the following final concentrations of $1.5,1$ and $0.5 \mu \mathrm{g} / \mathrm{ml}$. Cultures were maintained at $37^{\circ} \mathrm{C}$ without changes of medium during the entire drug incubation period (Elissondo et al., 2007). Culture tubes were followed macroand microscopically every day. Samples of cysts from each of the dosing groups and the controls were taken and then fixed for electron microscopy. The criteria for cysts vitality was assessed on the basis of structural vesicle integrity and the ultrastructural observation of the germinal layer as described by Elissondo et al. (2007). All experiments were performed in triplicate and were repeated three times.

\subsection{Morphologic study}

Samples of cysts recovered from each mouse were processed for scanning (SEM) and transmission (TEM) electron microscopy as described by Elissondo et al. (2007). Samples of cysts cultured in vitro were processed for SEM (Elissondo et al., 2007).

\subsection{Statistical analysis}

Data are reported as arithmetic mean $( \pm S D)$ and statistical analysis was performed using the Instat 3.0 Software (Graph PadSoftware, CA, USA). The data obtained from pharmacokinetic and clinical efficacy studies were compared by means of Kruskal-Wallis (non parametric ANOVA) followed by Dunn's multiple comparison test. Log-rank test was used to assess the survival differences of cysts after exposure to different concentration of ABZ-SO. These statistical analyses were performed using the BioEstat 5.0 software (Ayres et al., 2007). For all statistical comparisons, a $P$ value less than $0.05(P<0.05)$ was considered significant.

\section{Results}

\subsection{Pharmacokinetic study}

$\mathrm{ABZ}-\mathrm{SO}$ and $\mathrm{ABZ}-\mathrm{SO}_{2}$ were the main analytes detected in plasma and cyst after administration of ABZ-LNCs (oral or sc route) and ABZ-SUSP (oral route) to infected mice. In addition, ABZ was the analyte measured at the lowest concentrations in plasma of ABZLNC treated mice, being over a short period between 5 and $15 \mathrm{~min}$ post-treatment, with concentrations near to the limit of quantification. The trace concentrations detected during a short-time period precluded the development of a complete pharmacokinetic analysis of the data determined for this molecule after the oral administration of ABZ-LNC.

The concentration profiles (mean $\pm S D$ ) of ABZ-SO and ABZ$\mathrm{SO}_{2}$ either in plasma or within recovered cysts from ABZ-LNCs ${ }_{\text {oral }}$, ABZ-LNCs sc $_{\mathrm{sc}}$ or ABZ suspension groups are shown in Fig. 1. After ABZ-LNCs treatment (oral or Sc), ABZ-SO plasma concentration profiles were higher than those measured for $\mathrm{ABZ}-\mathrm{SO}_{2}$ (Fig. $1 \mathrm{a}$ and $\mathrm{b}$ ). For the oral and sc administration, ABZ-SO plasma concentration 

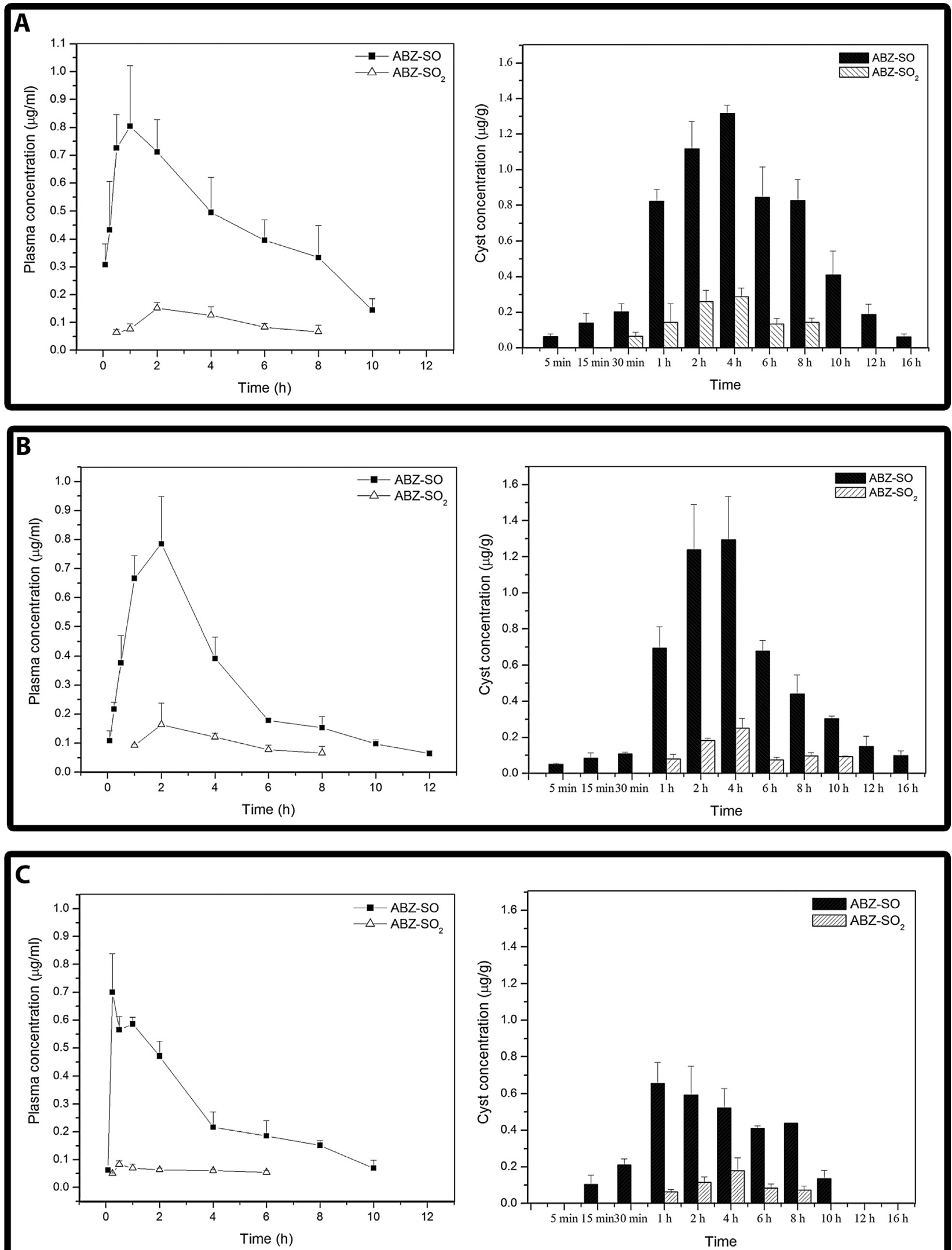

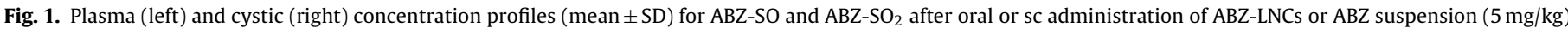
to infected mice ( $n=4$ per time point). (a) Oral administration of ABZ-LNCs. (b) Subcutaneous injection of ABZ-LNCs. (c) Oral administration of ABZ suspension. 
Plasma

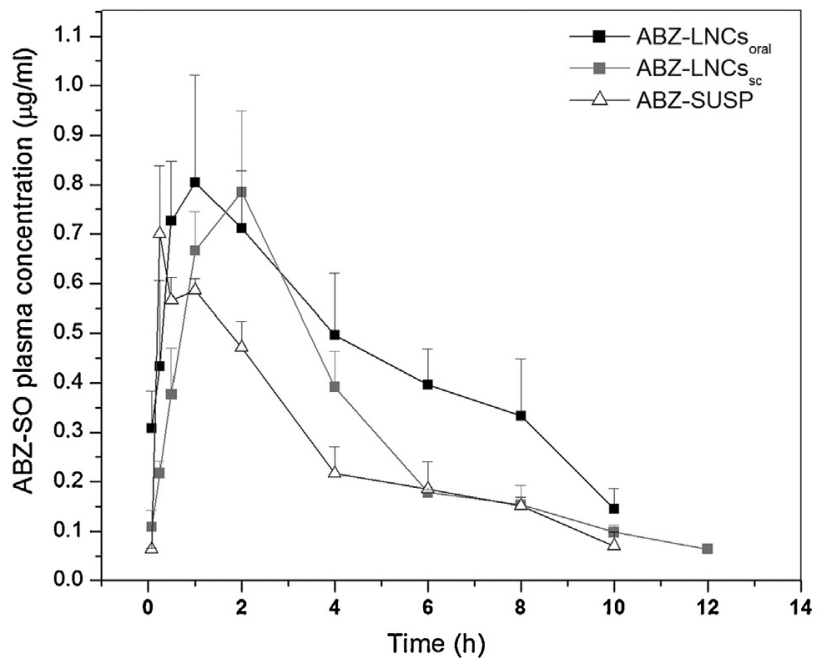

Cysts

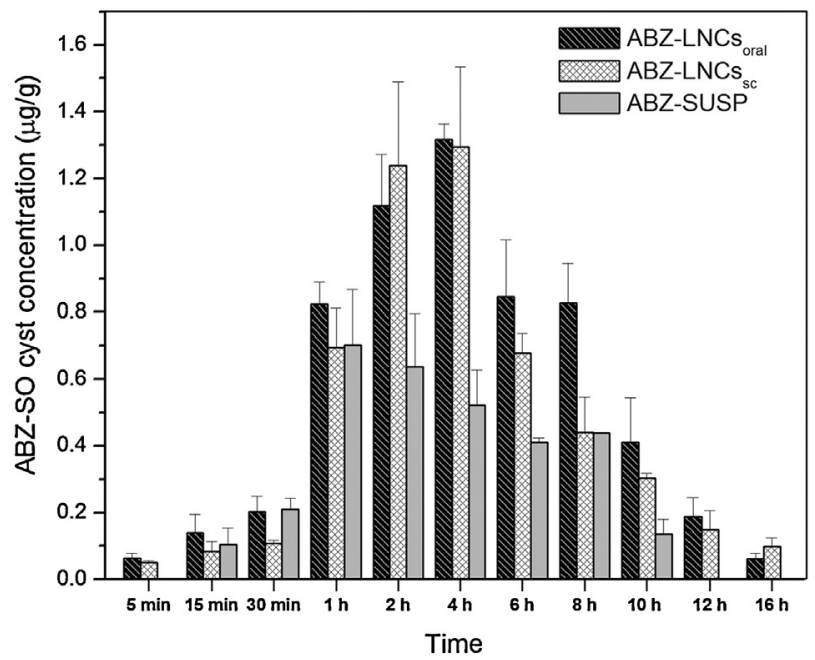

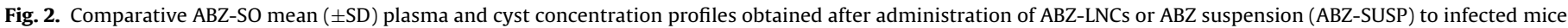
$(n=4$ per time point).

Table 1

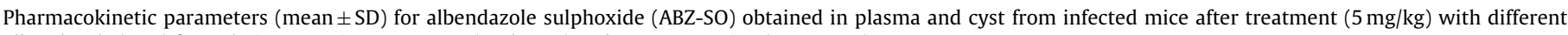
albendazole (ABZ) formulations to mice: ABZ-LNCs (oral or SC) and ABZ suspension (ABZ-SUSP).

\begin{tabular}{|c|c|c|c|c|c|c|}
\hline \multirow[t]{2}{*}{ Pharmacokinetic parameters } & \multicolumn{2}{|l|}{ ABZ-LNCs $s_{\text {oral }}$} & \multicolumn{2}{|l|}{$\mathrm{ABZ}-\mathrm{LNCS}_{\mathrm{sc}}$} & \multicolumn{2}{|l|}{ ABZ-SUSP } \\
\hline & Plasma & Cyst & Plasma & Cyst & Plasma & Cyst \\
\hline $\operatorname{AUC}_{0-L O Q}\left(\mu \mathrm{g} \mathrm{h} / \mathrm{ml}[\mathrm{g}]^{\mathrm{a}}\right)$ & $4.65 \pm 0.71 \mathrm{a}$ & $9.37 \pm 1.42 b$ & $3.6 \pm 0.33 c$ & $8.4 \pm 0.71 b$ & $2.37 \pm 0.35 \mathrm{~d}$ & $4.25 \pm 0.38 \mathrm{e}$ \\
\hline$C_{\max }\left(\mu \mathrm{g} / \mathrm{ml}[\mathrm{g}]^{\mathrm{b}}\right)$ & $0.82 \pm 0.1 \mathrm{a}$ & $1.27 \pm 0.09 \mathrm{~b}$ & $0.82 \pm 0.11 \mathrm{a}$ & $1.41 \pm 0.17 b$ & $0.68 \pm 0.11 \mathrm{a}$ & $0.73 \pm 0.08 \mathrm{a}$ \\
\hline$T_{\max }(\mathrm{h})$ & $1 \pm 0.71 \mathrm{a}$ & $3.5 \pm 1 \mathrm{~b}$ & $1.75 \pm 0.5 \mathrm{a}$ & $3.5 \pm 1 \mathrm{~b}$ & $0.44 \pm 0.37 \mathrm{c}$ & $2 \pm 1.41 \mathrm{~b}$ \\
\hline
\end{tabular}

AUC $_{0-\text { LOQ }}$ : area under the concentration vs. time curve from 0 up to the limit of quantification. $C_{\max }$ : peak plasma concentration; $T_{\max }$ : time to $C_{\max }$.

Different letters (a, b, c, d, e) indicate statistically significant differences $(P<0.05)$ between experimental groups.

a Plasma AUC is expressed as $\mu \mathrm{g} \mathrm{h} / \mathrm{ml}$ and cyst AUC as $\mu \mathrm{g} \mathrm{h} / \mathrm{g}$.

b Plasma $C_{\max }$ is expressed as $\mu \mathrm{g} / \mathrm{ml}$ and cyst $C_{\max }$ as $\mu \mathrm{g} / \mathrm{g}$.

increased to reach a $C_{\max }(0.82 \mu \mathrm{g} / \mathrm{ml})$ at 1 and $1.75 \mathrm{~h}$ post treatment, respectively. Low ABZ-SO ${ }_{2}$ concentrations were measured after oral $(0.16 \mu \mathrm{g} / \mathrm{ml})$ or sc $(0.19 \mu \mathrm{g} / \mathrm{ml})$ administration, being detectable up to $8 \mathrm{~h}$ post treatment. A similar pattern was observed in cysts, where ABZ-SO concentrations were 5-fold higher than those observed for $\mathrm{ABZ}-\mathrm{SO}_{2}$. After the oral administration of $\mathrm{ABZ}$ formulated as a suspension (ABZ-SUSP), ABZ-SO concentrations rapidly increased to reach a peak plasma concentration (Cmax) of $0.68 \mu \mathrm{g} / \mathrm{ml}$, as early as $0.44 \mathrm{~h}$ post treatment. Furthermore, low $\mathrm{ABZ}-\mathrm{SO}_{2}$ plasma concentrations detected between $15 \mathrm{~min}$ and $6 \mathrm{~h}$ were observed (Fig. 1c). In cysts, $\mathrm{ABZ}-\mathrm{SO}$ and $\mathrm{ABZ}-\mathrm{SO}_{2}$ achieved the peak concentration at 2 and $4 \mathrm{~h}$ post-treatment, respectively. Likewise, the $C_{\max }$ value for ABZ-SO ${ }_{2}$ in cysts $(0.21 \pm 0.06 \mu \mathrm{g} / \mathrm{g})$ resulted lower than that obtained for ABZ-SO $(0.73 \pm 0.08 \mu \mathrm{g} / \mathrm{g})$ (Fig. 1c).

The comparative plasma and cyst concentration profiles of ABZ-SO obtained after oral or sc administration of ABZ-LNCs and ABZ-SUSP to infected mice are shown in Fig. 2. Table 1 summarizes the plasma and cyst pharmacokinetics parameters $\left(C_{\max }\right.$, $T_{\max }$ and $\left.\mathrm{AUC}_{0-\mathrm{LOQ}}\right)$ obtained for $\mathrm{ABZ}-\mathrm{SO}$ after the oral or $\mathrm{SC}$ administration of ABZ as a LNC-based formulation or a conventional suspension in infected mice. Enhanced ABZ-SO concentration profiles were obtained in plasma and cysts after ABZ-LNC administration.

The sc administration of ABZ-LNCs to mice, did not improve the relative ABZ-SO plasma and cyst availability compared to that observed after the oral administration of the LCNs formulation. Similar $C_{\max }$ and $\mathrm{AUC}_{0-\mathrm{LOQ}}$ values were observed for both routes of administration (Table 1 ).
Higher systemic drug concentration was obtained after oral or sc administration of ABZ-LNCs compared to the ABZ suspension. $A U C_{0-L O Q}$ values for $A B Z-S O$ in $A B Z-L N C$ treated mice were increased more than 2 -fold compared with $A B Z$ suspension group. Likewise, the concentrations of ABZ-SO in cysts from both ABZ-LNC groups were greater than those measured in the ABZ-SUSP group. These results were reflected in higher $\mathrm{AUC}_{0-\mathrm{LOQ}}$ values compared to those obtained for ABZ-SUSP (Table 1).

Interestingly, $\mathrm{AUC}_{0-\mathrm{LOQ}}$ values for $\mathrm{ABZ}-\mathrm{SO}$ measured in cysts were $1.8,2,2.34$ fold greater than those obtained in plasma for the ABZ-SUSP, ABZ-LNCs oral and ABZ-LNCs $s_{s c}$ groups, respectively. Furthermore, ABZ-SO concentrations in cyst from mice treated with ABZ-LNC were 1.7 fold greater than those observed in plasma.

\subsection{In vivo efficacy study}

Hydatid cysts developed in all infected animals involved in the clinical efficacy study. Table 2 summarizes the cyst weights $($ mean $\pm S D)$ recorded after treatments on the different experimental groups involved in the efficacy study. There were no statistically differences $(P>0.05)$ between the control groups (distilled water $=8.98 \pm 4.61 \mathrm{~g}$; blank $\mathrm{LNCs}_{\text {oral }}=10.13 \pm 2.98 \mathrm{~g}$; blank $\mathrm{LNCS}_{\mathrm{sc}}=9.38 \pm 4.38 \mathrm{~g}$ ). On the other hand, mice that received ABZ suspension exhibited a reduction (59\%) in the weight of their cyst masses relative to control mice. However, no significant difference between control $(8.98 \pm 4.61 \mathrm{~g})$ and ABZ-SUSP groups $(5.38 \pm 2.6 \mathrm{~g})$ was detected $(P>0.05)$. In contrast, ABZ-LNC treatment resulted in 


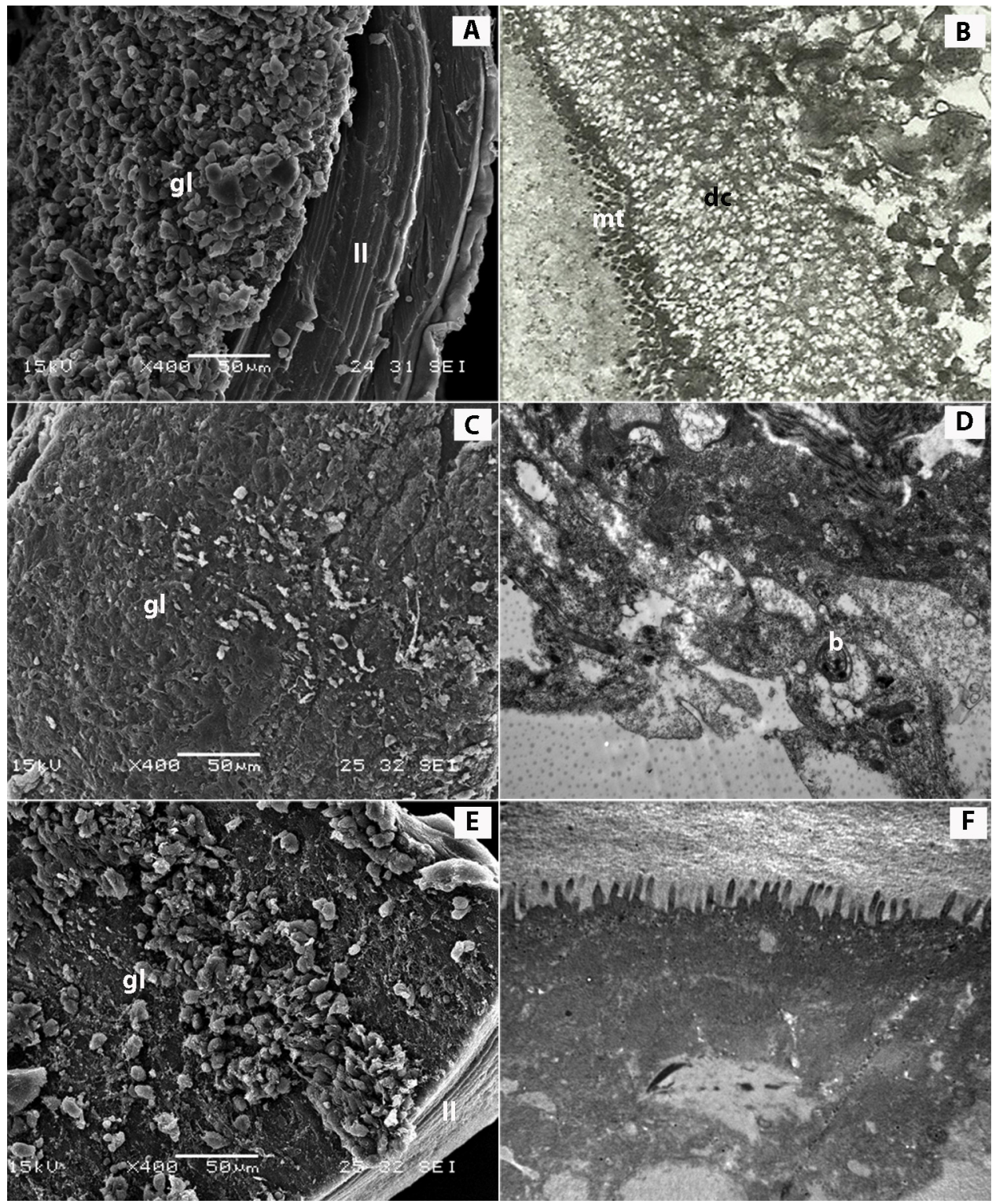

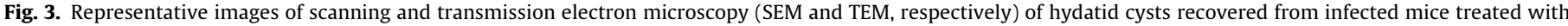

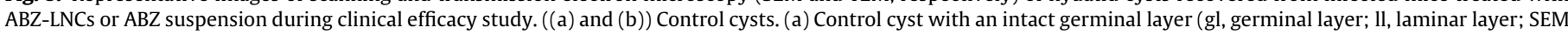

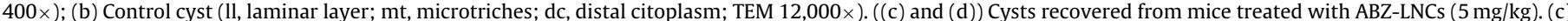

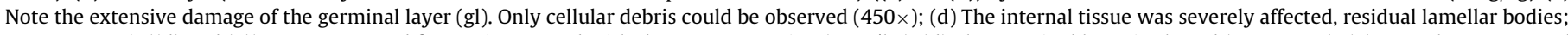

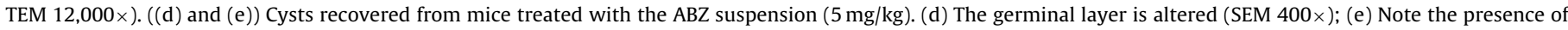
vacuoles (arrows) (TEM 12,000 $\times$ ).

Table 2

Clinical efficacy study. Mean $( \pm S D)$ weights $(\mathrm{g})$ of the hydatid cysts recovered from infected mice from control, ABZ-LNCs and ABZ suspension (ABZ-SUSP) treated groups $(n=10)$. Treatments were performed after 5 months post-infection during 30 days every $24 \mathrm{~h}$, at the doses rate of $5 \mathrm{mg} / \mathrm{kg}$.

\begin{tabular}{|c|c|c|}
\hline & \multicolumn{2}{|l|}{ Clinical efficacy } \\
\hline & Wet weight $(\mathrm{g}$ ) of cysts mean $\pm \mathrm{SD}$ & $\%$ of efficacy \\
\hline Untreated control group & $8.98 \pm 4.61 \mathrm{a}$ & - \\
\hline Blank-LNCs oral & $10.13 \pm 2.98 \mathrm{a}$ & - \\
\hline Blank-LNCs $\mathrm{sc}_{\mathrm{sc}}$ & $9.38 \pm 4.38 \mathrm{a}$ & - \\
\hline ABZ-SUSP & $5.38 \pm 2.6 \mathrm{a}$ & 46.9 \\
\hline ABZ-LNCs ${ }_{\text {oral }}$ & $0.91 \pm 1.16 b$ & 91.0 \\
\hline $\mathrm{ABZ}-\mathrm{LNCs}_{\mathrm{sc}}$ & $1.26 \pm 1.01 \mathrm{~b}$ & 87.6 \\
\hline
\end{tabular}

Different letters (a, b) indicate statistically significant differences $(P<0.05)$ between experimental groups. a statistically significant reduction $(P<0.01)$ on the cysts weight compared to those obtained for unmedicated mice. No difference between the routes of administration was observed $(P>0.05$; ABZ$\left.\mathrm{LNCS}_{\text {oral }}=0.91 \pm 1.16 \mathrm{~g} ; \mathrm{ABZ}-\mathrm{LNCs}_{\mathrm{sc}}=1.26 \pm 1.01 \mathrm{~g}\right)$.

All cysts in the samples removed from control mice appeared turgid, showing no observable collapse of the germinal layer and no changes in the ultrastructure were detected (Fig. 3a). TEM analysis of cysts recovered from the untreated control group revealed typical features of E. granulosus metacestodes, with a distinct acellular outer laminated layer and a germinal layer without alterations (Fig. 3b). Conversely, TEM and SEM analysis of the cysts recovered from mice treated either with ABZ-LNCs (Fig. 3c and d) or ABZ-SUSP (Fig. $3 e$ and f) revealed changes in the germinal layer. However, the damage extension appears to be greater after ABZ-LNCs compared to the $A B Z$ suspension treatment. The same ultrastructural alterations were observed when ABZ-LNCs were administered by sc 


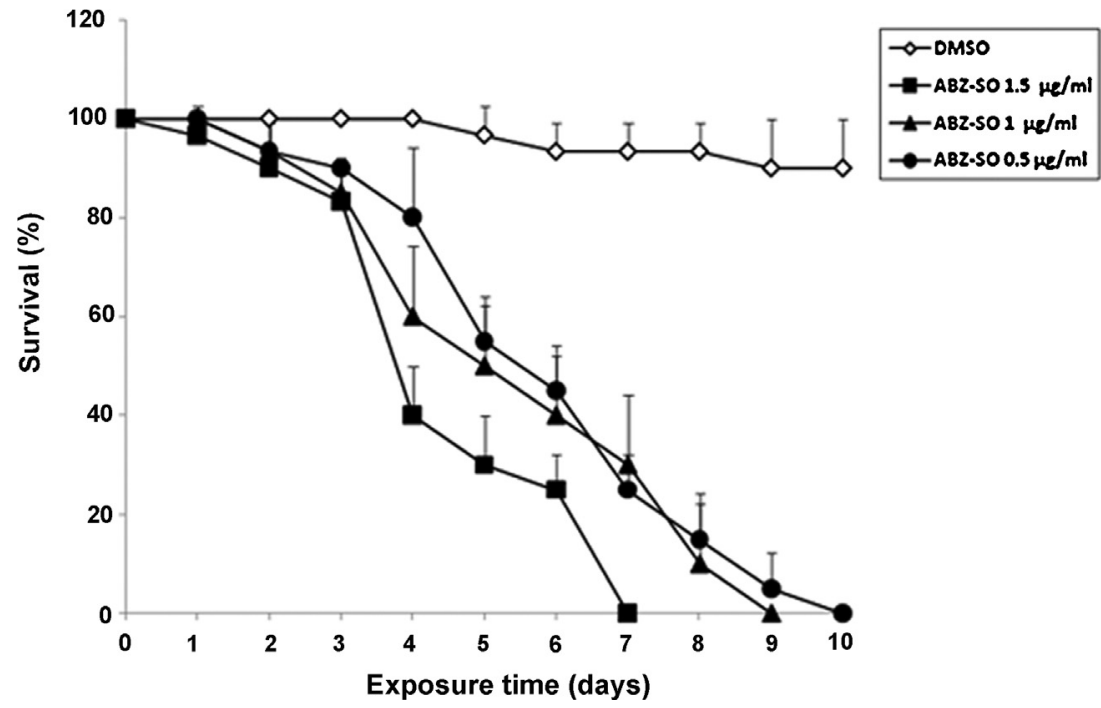

Fig. 4. Survival of E. granulosus cysts after exposure to ABZ-SO. Viability was measured on the basis of vesicle integrity (DMSO: dimethyl sulphoxide).

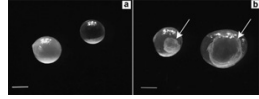

Fig. 5. Morphological effects of ABZ-SO treatment on E. granulosus cysts. (a) Control cysts (4 days post-incubation). (b) Cysts incubated with $1.5 \mu \mathrm{g} / \mathrm{ml}$ of ABZ-SO (arrows, germinal layer; 4 days post-incubation) bar: $1 \mathrm{~mm}$.

route (data not shown). Regarding the ultrastructural study by SEM, debris of cells could be observed for ABZ-LNCs treatments (Fig. 3c) while only few cells with an intact morphology were detected for ABZ suspension treatment (Fig. 3e). TEM analysis of cysts recovered from ABZ-LNCs treated group showed marked alteration in the germinal layer with internal tissue extensively distorted, vacuolated areas and the presence of lamellar bodies (Fig. 3d). On the other hand, treatment with ABZ suspension provoked slight utrastructural alterations with the presence of vacuolated areas (Fig 3f).

\subsection{In vitro incubation of cysts with ABZ-SO}

Survival of cysts incubated with the different concentrations of ABZ-SO is shown in Fig. 4. The viability of cysts incubated with DMSO was $>90 \%$ after 10 days. Fig. 5a shows untreated cysts, turgid, with a smooth surface and intact germinal and laminated layers. In contrast, viability of ABZ-SO-treated cysts was reduced (Fig. 4). Dose- and time-dependent effects were observed. The loss of turgidity and collapse of the germinal layer could be observed earlier in cyst treated with ABZ-SO at the highest concentrations (Fig. 5b). At the lower concentration, similar morphological changes occurred, although at a lower rate (data not shown).

Control cultures exhibit no ultrastructural alterations in parasite tissue during the whole incubation period (Fig. 6a and b). Studies by SEM revealed that the germinal layer of treated cysts lost the multicellular structure feature (Fig. $6 \mathrm{c}-\mathrm{g}$ ). There was a correlation between the intensity of damage and the concentration assayed.

\section{Discussion}

The anthelmintic activity of BZ compounds not only depends on its binding to parasite $ß$-tubulin but also on their ability to reach high and sustained concentrations at the site of parasite location that allow the delivery of effective concentrations of the compound at the target within the parasite cells, in sufficient time, to cause the therapeutic effect (Thompson and Geary, 1995). The low water solubility of BZ seriously limits their absorption and systemic bioavailability. Clearly, the poor oral absorption of ABZ after administration in the conventional suspension/tablet formulations is a serious disadvantage for the treatment of systemic infections such as CE. Therefore, the use of pharmacotechnical strategies to overcome this limitation may markedly improve the in vivo efficacy of ABZ against $C E$.

Differentes nanoscale drug delivery systems such as liposomes (Wen et al., 1996; Dvorožňáková et al., 2004), self-emulsifying (Meena et al., 2012) or self-microemulsifying (Mukherjee and Plakogiannis, 2010) delivery system form emulsions have been developed in order to enhance ABZ solubility. However, solubility alone is not sufficient; the drug must remain stable in gastrointestinal fluids, and when it reaches absorption areas (mainly the duodenum and jejunum), it needs to overcome the mucus layer to reach the apical side of enterocytes (Groo et al., 2013). Moreover, one of the main limitations of liposomes is their poor loading capacity toward hydrophobic drugs that cannot be dissolved in large amounts in the phospholipid bilayer or sequestered in the liposomal aqueous core (Sharma et al., 1997).

LNC are synthetic particles having a hybrid structure between polymer nanoparticles and liposomes. These capsules are composed of FDA-approved medium chain triglycerides and a combination of hydrophilic/lipophilic surfactants. Heurtault et al. (2002, 2003) demonstrated that mean size and size distribution of LNC can be precisely controlled and that the semi-rigid shell imparts remarkable physical stability to the formulations. Such nanocapsules can accommodate relatively high concentrations of lipid-soluble drugs in their oily core. Unlike liposomes and most nanoparticle formulations, these nanostructures, which present a monodisperse size distribution, are prepared via a solvent-free process that does not require any purification step (Hirsjärvi et al., 2013). The fabrication of NCL, based on low-energy organic solventfree phase inversion process, can be easily scaled up (Hirsjärvi et al., 2013). In addition, Dulieu and Bazile (2005) studied the freezedrying of aqueous suspensions of LNC and found that it was possible to freeze-dry them without altering their characteristics. Therefore, LNC could be stabilized and incorporated in any dry dosage forms for administration to patients: powder, hard gelatin capsules, even tablets. Moreover, the lyophilized form of LNC could be used to make an aqueous oral suspension to be reconstituted just before administration. Therefore, this stable form of LNC (obtained by freeze-drying) could allow an easy daily administration to patients. 

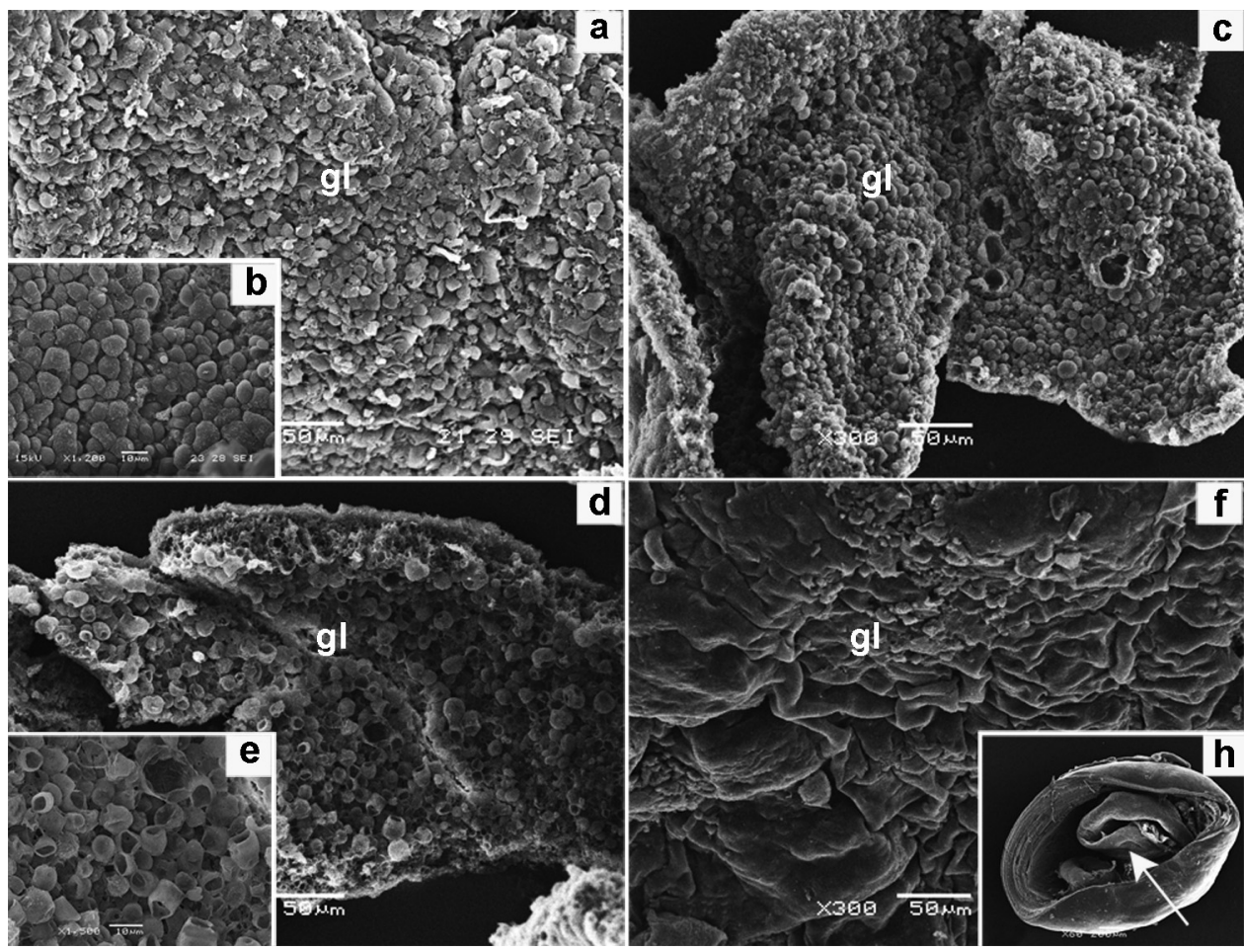

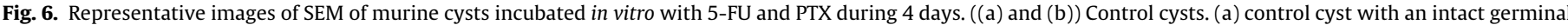

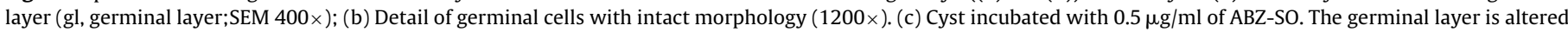

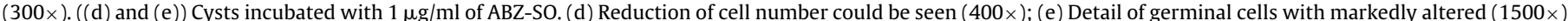

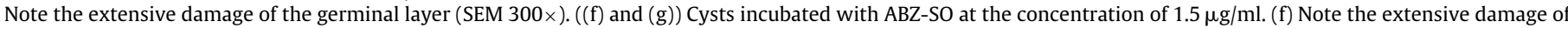
the germinal. Only cellular debris could be observed $(300 \times)$; $(\mathrm{g})$ Germinal layer detached from laminated layer (gl germinal layer; $60 \times$ ).

In a previous study, ABZ-LNCs with approximately $50 \mathrm{~nm}$ size, low polydispersity index and high drug payload $(>90 \%)$ were obtained (unpublished data). In the current experimental work, we characterized the plasma and cyst exposure of $\mathrm{ABZ}, \mathrm{ABZ}-\mathrm{SO}$ and $\mathrm{ABZ}-\mathrm{SO} 2$, and the clinical efficacy of $\mathrm{ABZ}$ against $\mathrm{CE}$ developed in mice, after the administration of $5 \mathrm{mg} / \mathrm{kg} \mathrm{ABZ}$ as a LNC-based formulation or a conventional suspension. Other authors have compared the effect of different new drugs or formulations versus $A B Z$ at doses up to $200 \mathrm{mg} / \mathrm{kg}$ (Hemphill et al., 2014). As we mentioned above, ABZ is barely absorbed from the gastrointestinal tract since it is a poorly water-soluble drug. It was demonstrated that for monogastric species, an increment in the dose is not correlated to an increment in the AUC (McKellar et al., 1990). Moreover we demonstrated that concentrations of $\mathrm{ABZ}$ as low as $0.5 \mathrm{mg} / \mathrm{kg}$ exert a deleterious effect on hydatid cysts on the murine model of cystic echinococcosis (Ceballos et al., 2008).

During the pharmacokinetic study, the parent drug was not detected at any time post-treatment with ABZ suspension, in either plasma or cysts. This is a consequence of intestinal and hepatic first-pass metabolism which is according to the results reported by other authors in different animal species (Molina et al., 2007). After administration of LNC-ABZ, lower concentrations of ABZ were detected in plasma of mice over a short period. ABZ-SO (active metabolite) and $\mathrm{ABZ}-\mathrm{SO}_{2}$ were the main analytes identified in plasma and cysts from treated groups. The administration of ABZLNCs either by oral or sc route, correlated with an increased plasma availability of ABZ-SO compared to that observed after the administration of the suspension. In fact, the relative bioavailability of the sulphoxide metabolite increased $96 \%$ after the treatment with ABZ-LNCs compared to ABZ-SUSP. These results agree with previous studies, where the use of different formulations was assessed to increase ABZ bioavailability (Shuhua et al., 2002; Ceballos et al.,
2008; Palomares-Alonso et al., 2010; Castro et al., 2012). As similar $\mathrm{C}_{\max }$ values for ABZ-SO were detected after the administration of both $A B Z$ formulations, the higher AUC value obtained after ABZLNCs could be explained by the longer ABZ-SO residence time in the bloodstream observed in these experimental groups. The concentrations of ABZ-SO in cysts from both ABZ-LNCs groups were greater than those measured in the ABZ-SUSP group. Unlike the data reported by Ceballos et al. (2011), we found that ABZ-SO exposure in cysts were greater than those observed in plasma in all the experimental groups. Interestingly, ABZ-SO peak concentrations measured in cysts from mice treated with ABZ-LNCs were 1.7 fold greater than those observed in plasma, whereas there was no difference between ABZ-SO cysts and plasma peak concentrations in the animals treated with the $\mathrm{ABZ}$ suspension.

The higher the concentration profiles achieved at the tissue/ fluid of the parasite location, the greater the amount of drug reaching the target parasite (Alvarez et al., 2007). Available scientific evidence indicates that higher drug bioavailability correlates with improved efficacy of BZD anthelmintics against CE developed in mice (Shuhua et al., 2002; Ceballos et al., 2008; Palomares-Alonso et al., 2010; Pensel et al., 2014). The enhancement in plasma drug exposure induced by the LNCs formulation leads to an amount of drug reaching the hydatid cysts and its overall anthelmintic effect. On the other hand, even though the treatment with ABZ did not result in a statistically significant reduction in cyst weight, evident ultrastructural damage could be detected in germinal layer of cysts. These results were consistent with the in vitro studies carried out in cyst incubated at the range concentrations measured in pharmacokinetic studies. In agreement with other researches, the effect of ABZ-SO was dose and time exposure manner (Elissondo et al., 2007, 2009). Moreover, there was a correlation between the intensity of damage and the concentration assayed. The ultrastructural 
changes induced in vitro and in vivo by ABZ-SO were similar to those described for other BZ compounds such as flubendazole (Elissondo et al., 2007, 2009).

The lipidic nature of the nanocapsules could explain the improvement of oral exposure of lipophiliccompound such as ABZ. The presence of lipids and surfactants in LNC could facilitate the gastrointestinal dissolution of ABZ (a physicochemical mechanism) (Peltier et al., 2006). Moreover, the capacity of LNCs to increase oral bioavailability of ABZ could also be explained by gastrointestinal stability of particles and an improvement of intestinal permeability LNCs increase ABZ transport across intestinal Caco-2 epithelial cells using vesicle- mediated transcytosis (Roger et al., 2009a,b).

As liver and lungs are the most frequent resident niches of the hydatid cyst in humans, new in vivo studies should be realized in other animal model of echinococcosis in order to establish the achievement of the drug inside cysts located in those target organs. However, we consider that even higher concentrations of ABZ-SO could be expected inside of liver and lung cysts. After oral administration of ABZ, an accumulation of ABZ-SO was demonstrated in liver and lungs of human patients (Meulemans et al., 1984).

In conclusion, the exposure of the hydatid cysts to enhanced drug concentrations obtained after the administration of ABZLNCs would correlate with increased efficacy in mice. This new pharmacotechnically-based strategy could be a potential alternative to improve the treatment of human $\mathrm{CE}$.

\section{Acknowledgements}

The authors gratefully acknowledge Dr. Gabriel Melendez and Dr. Sebastián González (SENASA, Argentina). This work was supported by the PICT 12 No. 1164 (ANPCyT, Argentina), PIP 0029 (CONICET, Argentina), and Universidad Nacional de Mar del Plata (Grant EXA 581/12 and EXA 672/14), Argentina.

\section{References}

Alanazi, F.K., El-Badry, M., Ahmed, M.O., Alsarra, I.A., 2007. Improvement of albendazole dissolution by preparing microparticles using spray-drying technique. Sci. Pharm. 75, 63-79.

Alvarez, L., Mottier, L., Lanusse, C., 2007. Drug transfer into target helminth parasites. Trends Parasitol. 23, 97-104.

Ayres, M., Ayres Jr., M., Ayres, D.L., Santos, A.S., 2007. BioEstat 5.0 aplicações estatísticas nas áreas das ciências biomédicas, fifth ed. Imprensa Oficial do Estado do Pará, Brazil.

Budke, C.M., Carabin, H., Ndimubanzi, P.C., Nguyen, H., Rainwater, E., Dickey, M., Bhattarai, R., Zeziulin, O., Qian, M., 2013. A systematic review of the literature on cystic echinococcosis frequency worldwide and its associated clinical manifestations. Am. J. Trop. Med. Hyg. 88 (6), 1011-1027.

Brunetti, E., Garcia, H.H., Junghanss, T., 2011. Cystic echinococcosis: chronic, complex, and still neglected. PloS Negl. Trop. Dis. 5, 1-5.

Brunetti, E., White Jr., A.C., 2012. Cestode infestations hydatid disease and cysticercosis. Infect. Dis. Clin. North. Am. 26, 421-435.

Castro, S.G., Sánchez Bruni, S., Urbizu, L.P., Confalonieri, A., Ceballos, L., Lanusse, C.E., Allemandi, D.A., Palma, S.D., 2012. Enhanced dissolution and systemic availability of albendazole formulated as solid dispersions. Pharm. Dev. Technol. 18 (2), 434-442.

Ceballos, L., Elissondo, M.C., Moreno, L., Dopchiz, M., Sánchez Bruni, S., Denegri, G., Alvarez, L., Lanusse, C., 2008. Albendazole treatment in cystic echinococcosis: pharmacokinetics and clinical efficacy of two different aqueous formulations. Parasitol. Res. 103, 355-362.

Ceballos, L., Elissondo, M.C., Sanchez Bruni, S., Denegri, G., Lanusse, C., Alvarez, L., 2011. Comparative performances of flubendazole and albendazole in cystic echinococcosis: ex vivo activity, plasma/cyst disposition, and efficacy in infected mice. Antimicrob. Agents Chemother. 55 (12), 5861-5867.

Cook, G.C., 1990. Use of benzimidazole chemotherapy in human helminthiases: indications and efficacy. Parasitol. Today 6, 133-136.

Dulieu, C., Bazile, D., 2005. Influence of lipid nanocapsules composition on their aptness to freeze-drying. Pharm. Res. 22, 285-292.

Dvorožňáková, E., Hrčková, G., Borošková, Z., Velebný, S., Dubinský, P., 2004. Effect of treatment with free and liposomized albendazole on selected immunological parameters and cyst growth in mice infected with Echinococcus multilocularis. Parasitol. Int. 53 (4), 315-325.

Elissondo, M.C., Ceballos, L., Alvarez, L., Sánchez Bruni, S., Lanusse, C., Denegri, G., 2009. Flubendazole and ivermectin in vitro combination therapy produces a marked effect on Echinococcus granulosus protoscoleces and metacestodes. Parasitol. Res. 105, 835-842

Elissondo, M.C., Ceballos, L., Dopchiz, M., Andresiuk, M.V., Alvarez, L., Sánchez Bruni, S., Lanusse, C., Denegri, G., 2007. In vitro and in vivo effects of flubendazole on Echinococcus granulosus metacestodes. Parasitol. Res. 100, 1003-1009.

Elissondo, M.C., Dopchiz, M., Ceballos, L., Alvarez, L., Sánchez Bruni, S., Lanusse, C.E., Denegri, G., 2006. In vitro effects of flubendazole on Echinococcus granulosus protoscoleces. Parasitol. Res. 98, 317-323.

Gibaldi, M., Perrier, D., 1982. Pharmacokinetics, 2nd ed. Marcel Dekker, New York, revised and expanded.

Groo, A.C., Saulnier, P., Gimel, J.C., Gravier, J., Ailhas, C., Benoit, J.P., Lagarce, F., 2013. Fate of paclitaxel lipid nanocapsules in intestinal mucus in view of their oral delivery. Int. J. Nanomed. 8, 4291

Hemphill, A., Stadelmann, B., Rufener, R., Spiliotis, M., Boubaker, G., Müller, J. Müller, N., Gorgas, D., Gottstein, B., 2014. Treatment of echinococcosis: albendazole and mebendazole-what else? Parasite. 21, 70

Heurtault, B., Saulnier, P., Pech, B., Proust, J.E., Benoit, J.P., 2002. A novel phase inversion-based process for the preparation of lipid nanocarriers. Pharm. Res. $19,875-880$.

Heurtault, B., Saulnier, P., Pech, B., Venier-Julienne, M.C., Proust, J.E., Phan-Tan-Luu, R., Benoit, J.-P., 2003. The influence of lipid nanocapsule composition on their sizedistribution. Eur. J. Pharm. Sci. 18, 55-61.

Hirsjärvi, S., Sancey, L., Dufort, S., Belloche, C., Vanpouille-Box, C., Garcion, E., Coll, J., Hindréa, F., Benoit, J.P., 2013. Effect of particle size on the biodistribution of lipid nanocapsules: comparison between nuclear and fluorescence imaging and counting. Int. J. Pharm. 453 (2), 594-600

Hureaux, J., Lagarce, F., Gagnadoux, F., Vecellio, L., Clavreul, A., Roger, E., Kempf, M. Racineux, J.L., Diot, P., Benoit, J.P., Urban, T., 2009. Lipid nanocapsules: ready-to-use nanovectors for the aerosol delivery of paclitaxel. Eur. J. Pharm. Biopharm. 73 (2), 239-246.

Jung, H., Medina, L., Garcia, L., Fuentes, I., Moreno-Esparza, R., 1998. Absorption studies of albendazole and some physicochemical properties of the drug and its metabolite albendazole sulphoxide. J. Pharm. Pharmacol. 50, 43-48.

Lacoeuillea, F., Hindrea, F., Moalc, F., Rouxd, J., Passirania, C., Couturiera, O., Cales, P., Le Jeune, J.J., Lamprechte, A., Benoit, J.P., 2007. In vivo evaluation of lipid nanocapsules as a promising colloidal carrier for paclitaxel. Int. J. Pharm. 344 143-149.

McKellar, Q.A., Harrison, P., Galbraith, E.A., Inglis, H., 1990. Pharmacokinetics of fenbendazole in dogs. J. Vet. Pharmacol. Ther. 13 (4), 386-392.

McManus, D.P., Gray, D.J., Zhan, W., Yang, Y., 2012. Diagnosis, treatment, and management of echinococcosis. BMJ 344, 39-44.

Meena, A., Sharma, K., Kandaswamy, M., Rajgopal, S., Mullangi, R., 2012. Formulation development of an albendazole self-emulsifying drug delivery system (SEDDS) with enhanced systemic exposure. Acta Pharm. 62, 563-580.

Meulemans, A., Giovanangeli, M.D., Mohler, J., Vulpillat, M., Hay, J.M., Saimot, A.G., 1984. High performance liquid chromatography of albendazole and its sulfoxide metabolite in human organs and fluids during hydatidosis. J. Liq. Chromatogr. 7, $569-580$

Molina, A.J., Merino, G., Prieto, J.R., Real, R., Mendoza, G., Alvarez, A.I., 2007. Absorption and metabolism of albendazole after intestinal ischemia/reperfusion. Eur. J. Pharm. Sci. 31 (1), 16-24.

Moro, P., Schantz, P.M., 2009. Echinococcosis: a review. Int. J. Infect. Dis. 13 125-133.

Mukherjee, T., Plakogiannis, F.M., 2010. Development and oral bioavailability assessment of a supersaturated self-microemulsifying drug delivery system (SMEDDS) of albendazole. J. Pharm. Pharmacol. 62 (9), 1112-1120.

Palomares-Alonso, F., González, C.R., Bernad-Bernad, M.J., Montiel, M.D.C., Hernández, G.P., González-Hernández, I., Castro-Torres, N., Pinzón Estrada, E. Jung-Cook, H., 2010. Two novel ternary albendazole-cyclodextrin-polymer systems: dissolution, bioavailability and efficacy against Taenia crassiceps cysts. Acta Trop. 113 (1), 56-60.

Peltier, S., Oger, J.M., Lagarce, F., Couet, W., Benoit, J.P., 2006. Enhanced oral paclitaxel bioavailability after administration of paclitaxel-loaded lipid nanocapsules. Pharm. Res. 23 (6), 1243-1250.

Pensel, P.E., Castro, S., Allemandi, D., Sánchez Bruni, S., Palma, S.D., Elissondo, M.C. 2014. Enhanced chemoprophylactic and clinical efficacy of albendazole formulated as solid dispersions in experimental cystic echinococcosis. Vet. Parasitol. 203 (1), 80-86.

Roger, E., Lagarce, F., Benoit, J.P., 2009a. The gastrointestinal stability of lipid nanocapsules. Int. J. Pharm. 379, 260-265.

Roger, E., Lagarce, F., Garcion, E., Benoit, J.P., 2009b. Lipid nanocarriers improve paclitaxel transport throughout human intestinal epithelial cells by using vesicle-mediated transcytosis. J. Control. Release 140, 174-181.

Sharma, A., Mayhew, E., Bolcsak, L., Cavanaugh, C., Harmon, P., Janoff, A.S. Bernacki, J., 1997. Activity of paclitaxel liposome formulations against human ovarian tumor xenograft. Int. J. Cancer 71, 103-107.

Shuhua, X., Jiqing, Y., Mingjie, W., Pieying, J., Fanghua, G., Junjie, C., Wei, J., Hotez, P., 2002. Augmented bioavailability and cysticidal activity of albendazole reformulated in soybean emulsion in mice infected with Echinococcus granulosus or Echinococcus multilocularis. Acta Trop. 82, 77-84.

Smyth, J.D., Howkins, A.B., Barton, M., 1966. Factors controlling the differentiation of the hydatid organism, Echinococcus granulosus, into cystic or strobilar stages in vitro. Nature 211, 1374-1377. 
Stojkovic, M., Zwahlen, M., Teggi, A., Vutova, K., Cretu, C.M., Virdone, R., Nicolaidou, P., Cobanoglu, N., Junghanss, T., 2009. Treatment response of cystic echinococcosis to benzimidazoles: a systematic review. PloS Negl. Trop. Dis. http://dx.doi.org/10.1371/journal.pntd.0000524.

Thompson, D., Geary, T., 1995. The structure and function of helminth surfaces. In: Harr, J., Muller, M. (Eds.), Biochemistry and Molecular Biology of Parasites. Academic, London, UK, p. 203.
Wen, H., New, R.R.C., Muhmut, M., Wang, J.H., Wang, Y.H., Zhang, J.H., Shao, Y.M. Craig, P.S., 1996. Pharmacology and efficacy of liposome-entrapped albendazole in experimental secondary alveolar echinococcosis and effect of coadministration with cimetidine. Parasitology 113, 111-121. 